\title{
Effect of Nipping on Growth, Assimilate Supply and Yield of Indian Mustard Genotypes
}

\author{
Uchab Lal Choudhary*, R.S. Jat, B.S. Rathore and Vinod Kumar
}

ICAR-Directorate of Rapeseed-Mustard Research, Bharatpur- 321 303, Rajasthan, India

*Corresponding author

\section{Keywords \\ Nipping, Mustard genotypes, Seed yield, Oil yield}

Article Info

Accepted:

26 June 2018

Available Online:

10 July 2018

\section{A B S T R A C T}

The response of nipping on morpho-physiological parameters and yield of twenty two genotypes of Indian mustard [Brassica juncea $($ L.) Czern\&Coss.] was studied in a field experiment. The results revealed that nipping significantly increased plant height, dry matters accumulation, number of primary and secondary branches per plant, number of sillquae per plant, seed yield $\left(2678.146 \mathrm{~kg} \mathrm{ha}^{-1}\right)$, harvest index $(30.57 \%)$ over nonnipping. respectively. Among the genotypes, RH 1223 recorded highest plant height, whereas, RH 1117 recorded highest dry matter, per plant. The highest stem girth, primary and secondary branches and main shoot length at harvest were found in RH 555, RH 1215 and RH 1223, respectively. In the yield attributes, the number of siliqua on main shoot, number of seeds siliqua ${ }^{-1}$, highest seed weight siliqua ${ }^{-1}$ were found in $\mathrm{RH} 1118$ and $\mathrm{RH}$ 1441, respectively. The RH 1118 recorded the highest biological yield $\left(10480.470 \mathrm{~kg} \mathrm{ha}^{-1}\right)$ and stover yield (7520.713 $\mathrm{kg} \mathrm{ha}^{-1}$ ), whereas, RH 1215 recorded the highest seed yield (3099.336 $\left.\mathrm{kg} \mathrm{ha}^{-1}\right)$, RH 1215 recorded the highest oil yield $\left(1299.41 \mathrm{~kg} \mathrm{ha}^{-1}\right)$, The maximum harvest index (34.87\%) was recorded in RH 1215 respectively.

\section{Introduction}

India is the third largest rapeseed-mustard producer in the world after Canada and China. This crop accounts for nearly one-third of the oil produced in India, making it the country's key edible oilseed crop. India accounts for $17.27 \%$ and $9.07 \%$ of the total acreage and production of rapeseed-mustard (USDA 2016) respectively. Rajasthan is one of the major mustard producing states in the country, contributing $46.2 \%$ of total production of India. Although, yield of mustard in Rajasthan is more than its national average yield, but we are still lagging behind as compared to the world's productivity. The burgeoning population of India would need about 58 million tonnes of oilseeds by the year 2020 for maintain their requirement of 15.5 $\mathrm{kg} / \mathrm{capita} /$ annum from present level of $13.4 \mathrm{~kg}$ and to meet the industrial need in a sustainable manner in the coming years.

In spite of latest high yield varieties of Indian mustard, the potential yield of these varieties is still unexplored due several constraints like lack of proper crop establishment techniques and nutrient, water and weed management 
techniques. Physiological manipulations may influence the plant source to sink relationship and ultimately yield. There is need to explore the advantage of simple agrotechniques like nipping, which suppresses the apical dominance and facilitates more lateral branches, ultimately resulting in more number of siliqua/plant and yield. There are reports on advantage of nipping in soybean, castor, chickpea and sunflower, however, so far no much research work has been done in Indian mustard. Therefore, a study was undertaken to find out the profitability of nipping in Indian mustard genotypes under rainfed conditions. Nipping in mutard is one of the important parameter for the enhancement of the yield and yield contributing parameters. Indian mustard one of the most important oil crops at national and international level, very little research work has been undertaken to study the subject. Therefore lacking to the above facts, the present investigation entitled 'Effect of nipping on growth, assimilate supply and yield of Indian mustard genotypes" was carried out with objectives to study the effect of nipping on growth parameters, yield parameters and yield of different genotypes of Indian mustard.

\section{Materials and Methods}

The present investigation was conducted at ICAR-Directorate of Rapeseed- Mustard Research, Sewer, Bharatpur (Rajasthan) during the year 2016-17. The experiment was laid out at research farm of DRMR, during 'Rabi' season of 2016-2017. The centre lies on $27^{0} 15^{\prime}$ North latitude, $77^{0} 3$ ' East longitudes and at an altitude of 178.37 meters above mean sea level. The region falls under Agro climatic Zone IIIA (semi-arid Eastern plain) with sub-tropical and semi-arid climate.

The climate of this zone is typically semi-arid and sub-tropical characterized by mid winter and moderate summers and associated with relatively high humidity during the month of July-September. The mean annual rainfall is $650 \mathrm{~mm}, 85$ percent mostly received from South-West monsoon during the last week of June to October. The average maximum and minimum temperature ranged between 20.8 to $40.9^{\circ} \mathrm{C}$ and 7.0 to $25.1^{\circ} \mathrm{C}$ during rabi2016-17, respectively. The mean daily evaporation from USWB class A pan evaporimeter ranged from 1.0 to $9.7 \mathrm{~mm}$ per day. The mean daily maximum and minimum relative humidity varied between $\left(\mathrm{RH}_{1}\right) 57.8$ and $\left(\mathrm{RH}_{2}\right) 20.4$ per cent. The bright sunshine hours varied from 5.9 in January to 10.3 in April during 2016-17. There was very low rainfall received during the month October $5.3 \mathrm{~mm}$ and $37.4 \mathrm{~mm}$ in January.

The treatments comprised of twenty two genotypes (RH- 555, RH- 1222-28, RH-1301, RH-749, IJ- 31, RH-1215, NRCHB-101, RH1210, RH-1053, RH-1223,NRCDR-2, RH601, RH-1140, RH-1118, RH-345, RH-1441, RH-1060, RH-1117, RH-1019, RH-1134, RH1138, RH-1172) tested with nipping and without nipping in a Factorial Randomized Block Design and replicated thrice. The crop was sown on October 14, 2016 as per treatments and harvested on March 08, 2017.A uniform basal dose of $40 \mathrm{~kg} \mathrm{~N}+40 \mathrm{~kg}$ $\mathrm{P}_{2} \mathrm{O}_{5} /$ ha through urea and SSP was drilled prior to sowing. The remaining $40 \mathrm{~kg} \mathrm{~N} / \mathrm{ha}$ was given by top dressing through urea at 30 DAS. Nipping was done by plucking the apical bud at 45 DAS with the help of a sharp blade. Five plants from the sampling rows were uprooted and used to compute the biometric and yield observations.

\section{Results and Discussion}

The nipping of genotypes responded differently and recorded significantly higher plant height compared non-nipping. Among the varieties RH 1223 recorded highest plant height $(233 \mathrm{~cm})$ at harvest followed by $\mathrm{RH}$ 
1134 and RH 1140. At harvest nipping recorded highest primary branch which was $9.09 \%$ higher over non-nipping. Among the varieties RH 1215 recorded highest primary branch (14) at harvest. Followed by RH 1210 (14) and NRCHB 101 (14) respectively. At harvest nipping recorded highest secondary branch which was $11.53 \%$ higher over nonnipping. Among the varieties NRCHB 101recorded highest secondary branch (31) at harvest followed by RH 1215 (31) and RH 1223 (30), respectively. Nipping recorded highest siliqua on main shoot which was 23.80 $\%$ higher over non-nipping. Among the varieties RH 1118 recorded highest siliqua on main shoot (53). Followed RH 1172 (52) and RH 749 (51) respectively.

Nipping and genotypes significantly influenced the dry matter at all the growth stages. At 80 DAS nipping recorded highest dry matter which was $1.06 \%$ higher over nonnipping. Among the genotypes RH1301 recorded highest dry matter (326 g) at 80 DAS followed RH 1215 (307 g) and RH 1053 (306 g) respectively. At 120 DAS nipping recorded highest dry matter which was $6.79 \%$ higher over non-nipping. Among the genotypes RH 1117 recorded highest dry matter $(681 \mathrm{~g})$ at 120 DAS followed by RH 1172 (594 g) and
DRMRIJ 31 (577 g) respectively. Nipping and genotypes significantly influenced the per cent weight of seed to siliqua significantly at harvest. Nipping increased the weight of seeds to the weight of siliqua. Among the genotypes RH 1222-28 recorded highest per cent seed to siliqua weight $(56.4 \%)$ under nipping, however, under non-nipping DRMR IJ 31 recorded highest seed to siliqua weight $(57.4 \%)$. It showed that some of the genotypes recorded more diversion of assimilated to seeds than siliqua under nipping whereas others not.

Non-nipping/Nipping and varieties significantly influenced the seed yield and harvest index. Nipping recorded highest seed yield (2678.146 kg/ha) which was $12.38 \%$ higher over non-nipping. Among the varieties RH 1215 recorded highest seed yield (3099 $\mathrm{kg} / \mathrm{ha})$ followed DRMRIJ 31 (3018 kg/ha) and RH 1118 (2959 kg/ha). Non-nipping/Nipping and varieties significantly influenced the harvest index $\%$ at all the growth stages. Nipping recorded highest harvest index \% (30.6\%) which was $4.40 \%$ higher over from non-nipping. Among the varieties RH 1215 recorded highest harvest index \% $(34.9 \%)$ at followed DRMRIJ 31 (34.7\%) and NRCHB 101 (34.2\%) (Fig. 1).

Fig.1 Effect of nipping of seed yield and harvest index of genotypes of Indian mustard.

LSD (0.05) for seed yield $=671$, bars represents the standard error

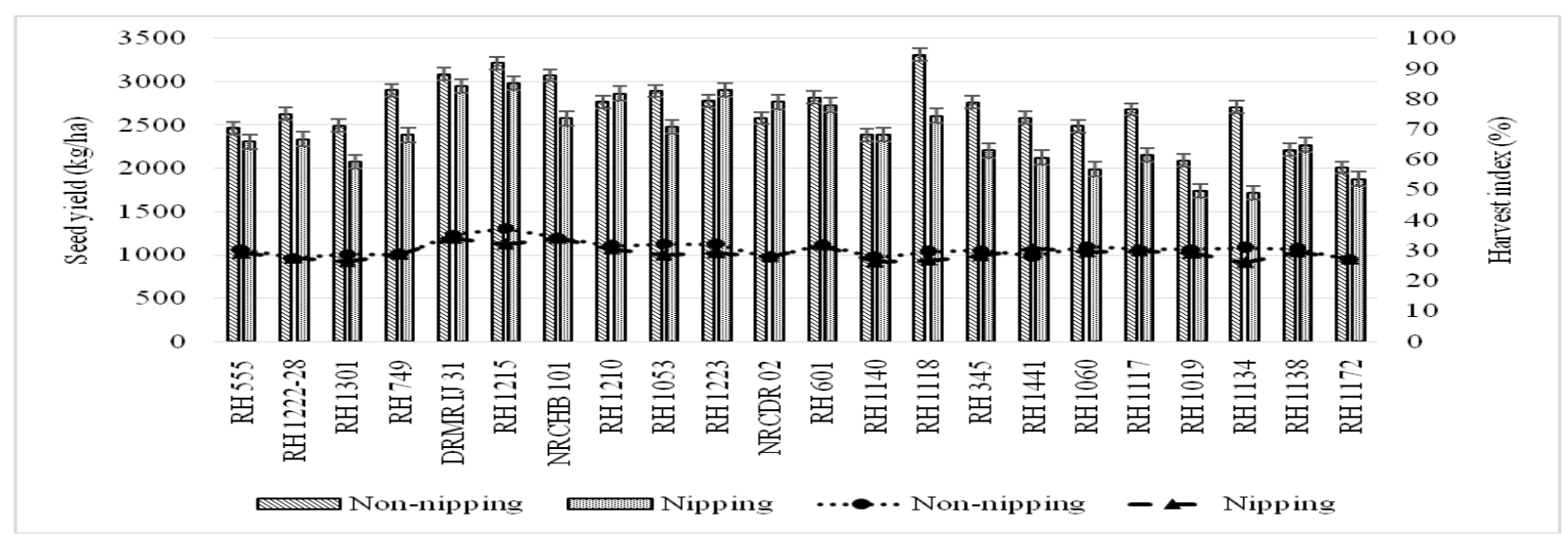


Table.1 Effect of nipping on growth parameters of mustard genotypes at harvest

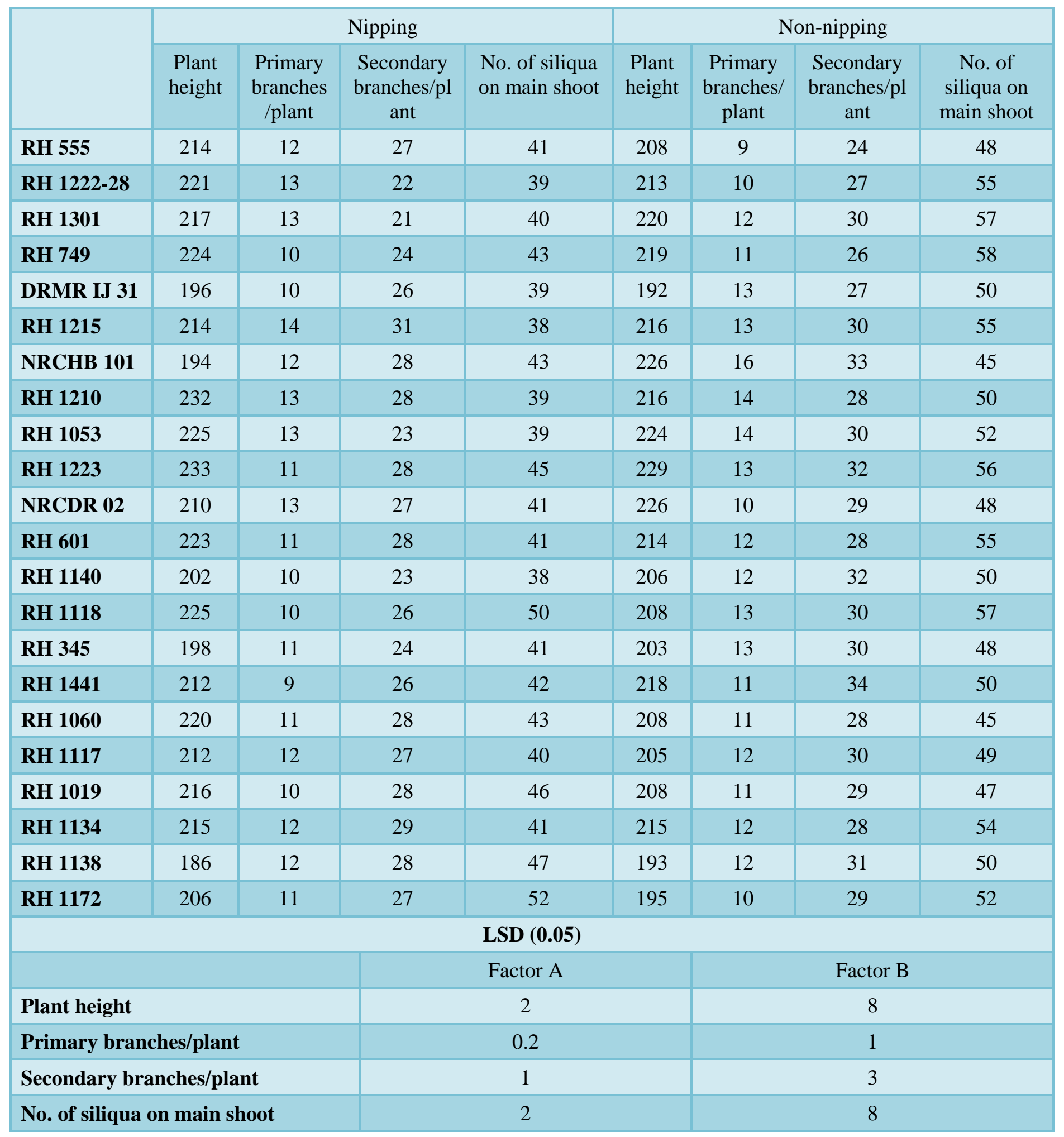


Table.2 Effect of nipping on yield attributes of genotypes of Indian mustard

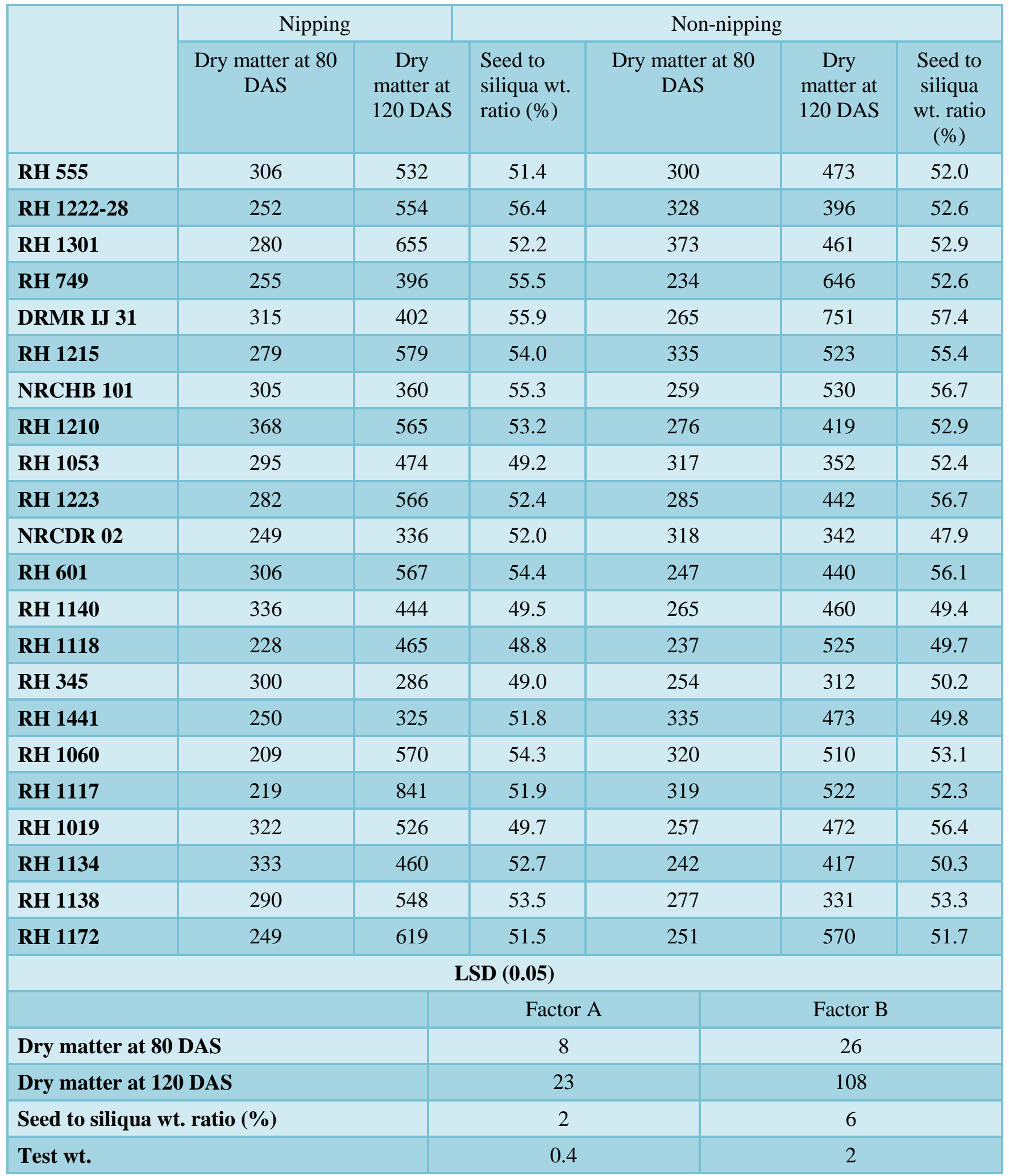




\section{Growth parameters}

Significantly higher plant height, dry matters accumulation and number of primary and secondary branches per plant recorded at all the growth stages of plant as a result. Among several seed production approaches, terminal bud nipping is being commonly practiced in several crops to increase the seed yield and quality. In mustard, nipping of young tender top shoots though traditionally practiced by the farmers but its associated beneficial effects are scientifically documented. Apical bud nipping is known to alter the source-sink relationship by arresting the vegetative growth and hastening the reproductive phase. It also helps in production of more pod bearing branches thus, resulting in increased photosynthetic metabolic activity, accumulation of more photosynthates and metabolites, ultimately resulting in better seed quality with higher seed yield. Similar results were also obtained by (Thakral et al., 1991).The reduction in plant height in nipped plants is mainly due to elimination of apical dominance and diversion of the plant metabolites from vertical growth to horizontal growth and recording more number of branches per plant. As the apical dominance is removed usually the plant itself adjusts to encourage the growth of auxiliary buds which may be converted into branches. Similar results were obtained by Arjun Sharma et al., (2003) respectively (Table 2 ).

\section{Yield attributes and yield}

Increase in the seed yield by nipping might be due to increase in number of productive branches, leaf thickness, number of pods per plant, number of seeds per pod and total dry matter accumulation (Table 2). Similarly increase in yield due to nipping was also observed by Reddy (1997) and Arjun Sharma et al., (2003) noticed the increase in seed yield due to significant reduction in plant height and increase in the number of primary and secondary branches and pods per plant. Similar results were also obtained by Himayatullah et al., (1989) and Aurangzeb et al., (1996) respectively.

In conclusion, the experiment of nipping significantly increased plant growth and yield parameters and yield, oil content and uptake over non-nipping. The genotypes varied in the growth pattern and yield and quality. RH 1215 recorded highest dry matter, leaf area index and siliqua weight plant $^{-1}$, seed yield and oil yield. The stem girth, primary and secondary branches and main shoot length were highest in RH 1215, RH 1215 and RH 1223, respectively at harvest. The maximum yield attributes were found in $\mathrm{RH} 1215$, whereas biological yield (10480 kg ha $\left.{ }^{-1}\right)$ and stover yield $\left(7520 \mathrm{~kg} \mathrm{ha}^{-1}\right)$ were found maximum in RH 1118, The maximum harvest index $(34.87 \%)$ was recorded in RH 1215 and DRMRIJ 31, respectively.

\section{References}

Arjun Sharma, Potdar, M.P., Pujari, B.T. and Dharmaraj, P.S. and Sharma, A., 2003, Studies on response of pigeon pea to canopy modification and plant geometry. Karnataka Journal of Agricultural Sciences, 16: 1-3.

Aurangzeb, M., Naeem-Ur-Rehman and Ikramullah, A, 1996, Causes of low gram productivity in rainfed D.I. Khan: results from a farm level survey. Journal of Rural Development and Administration, 28: 91-98.

Himayathullah, Samina-Praveen and MunirAhmed, 1989, Factors related to low chickpea productivity in rainfed Bannu: results from farm level survey. Sharhad J. Agric., 5: 29-32.

Reddy, A. G. R. and Reddy, T. V., 1977, Studies on grain moulds of sorghum. Sorghum News lett., 20: 10-11. 
Thakral, K. K., Singh, G. R., Pandey, U. C. and Srivastava, V. K., 1991, Effect of nitrogen levels and

cutting on the production of green leaves and seed yield of coriander $\mathrm{cv}$. Natural selection.

Haryana Agric. Univ. J. Res., 22(1): 35-39.

\section{How to cite this article:}

Uchab Lal Choudhary, R.S. Jat, B.S. Rathore and Vinod Kumar. 2018. Effect of Nipping on Growth, Assimilate Supply and Yield of Indian Mustard Genotypes. Int.J.Curr.Microbiol.App.Sci. 7(07): 3758-3764. doi: https://doi.org/10.20546/ijcmas.2018.707.435 